American Journal of Infectious Diseases 4 (2): 109-116, 2008

ISSN 1553-6203

(C) 2008 Science Publications

\title{
A Contemporary Analysis of Sexual Trends and Transmitted Infections Among Outpatient at Two Public Hospitals in Jamaica
}

\author{
${ }^{1}$ Tazhmoye Crawford, ${ }^{1}$ Michael T. Gardner and ${ }^{2}$ Donovan A. McGrowder \\ ${ }^{1}$ Department of Basic Medical Sciences, Faculty of Medical Sciences, \\ University of the West Indies, Kingston 7, Jamaica \\ ${ }^{2}$ Department of Pathology, Faculty of Medical Sciences, \\ University of the West Indies, Kingston 7, Jamaica
}

\begin{abstract}
Research aimed at investigating sexual behavior and assessing intervention to improve sexual and reproductive health among young adults in Jamaica has increased in recent decades. This study was carried out to assess both positive and negative sexual outcomes e.g. sexual activity and sexual satisfaction related to sexual behavior such as multiple partners and the use or non-use of condoms among young adults. As part of the Reproductive Health Survey, data on the socio-demographic characteristics, sexual activity and behavior were assessed using a 56-item questionnaire on 213 randomly selected young adults from the 14 parishes in Jamaica attending two major public hospitals. The majority of the respondents had their first sexual experience when they were 15-18 years old. Among the men, the majority achieved full sexual satisfaction $(100.0 \%)$ and had sex daily $(49.6 \%)$. The majority of women were unable to achieve full sexual satisfaction $(69.3 \%$, $\left.\chi^{2}=138.85, \mathrm{p}<0.05\right)$ yet had sexual intercourse more than once per week $\left(76.1 \%, \chi^{2}=58.05, \mathrm{p}<0.05\right)$. The majority of respondents had 2-3 sexual partners $(51.2 \%)$, used condoms $(56.7 \%)$ and ranked highest among those with sexually transmitted infections (85.9\%). Comprehensive behavioural interventions should target these young adults who are engaged in high sexual risk behaviors.
\end{abstract}

Key words: Young adults, adolescents, Jamaica, Sexually transmitted infections, high risk behavior

\section{INTRODUCTION}

Issues of sexuality have been one of the most fundamental aspects of human existence, which is directly related to both the physical and psychological well-being of an individual. The ability of individuals or couples to pursue a fulfilling and safe sex life is central to the achievement of sexual health. Men and women are indispensable partners in sexual relationships, marriage and family building. It has been well-established that positive, healthy sexuality attitudes within marriage are positively associated with several dimensions of marital well-being inclusive of marital satisfaction and happiness ${ }^{[1]}$. There is also a growing body of research demonstrating that sexual expression may have health benefits for improving quality of life, self-esteem, reducing stress, depression, and suicide ${ }^{[2]}$. Some studies even suggest that sexual activity may be associated with reducing the risk of heart disease and cancer, the two leading causes of death in the United States of America ${ }^{[3-4]}$.
Currently, research in human sexuality remains largely focused on the potential negative outcome of sexual expression. Adolescents and young adults represent a large and growing proportion of the population of developing countries such as Jamaica. The sexual and reproductive health of young people is under threat in part because of their perceived increased vulnerability to the risk of sexually transmitted infections (STIs), including acquired immunodeficiency syndrome (AIDS). Lower socio-economic status and/or lower level of educational attainment are well recognized as generally associated with risky sexual behaviors ${ }^{[5]}$. Early sexual activity, combined with a lack of relevant information, services and skills to avoid risky situations, place Jamaican adults at risk of unintended pregnancies, STIs including human immunodeficiency virus (HIV) and other threats to their sexual and reproductive health ${ }^{[6]}$. Considering the wide range of sex-related issues that are of great social and public health concern today, the need for data on sexual habits, frequency and behaviours in the general population is of considerable importance. The

Corresponding Author: Tazhmoye Crawford, Faculty of Medical Sciences, Department of Basic Medical Sciences, University of the West Indies, Mona, Kingston 7, Jamaica Tel: 1-876-362-3628 
information on such behaviors is necessary for understanding the cultural context of sexual activity and in order to inform educational efforts to prevent STIs. Sexual activity and sexual behavior are difficult to measure accurately, and self-reports serve as the only source of information. Presently, no independent record of sexual activity exists to serve as the "gold standard" of measurement in Jamaica.

This study is a sexual and reproductive health survey that focuses on sexual outcomes such as frequency of sexual activity and sexual satisfaction in relationships. It also assesses the negative health outcomes related to sexual behaviors of young adults such as early initiation of sexual activity, multiple partners, use or non-use of condoms, and the smoking of marijuana. The socio-demographic characteristics such as age, marital status, occupation, level of educational attainment and number of children were also assessed.

\section{MATERIALS AND METHODS}

Data was collected as part of a survey about sexual activity and behavior among young adults in Jamaica by the authors. The descriptive survey research method was employed for the study and fieldwork and was conducted between February and April, 2005. A standardized, structured questionnaire with open and close-ended questions, which captured sociodemographic and reproductive health information, was used for data collection. The sample consisted of a total of 265 randomly selected patients from the 14 parishes in Jamaica who visited two public hospitals. Questionnaires were distributed by medical professionals on duty. Two hundred and thirteen were satisfactorily completed and used in the analysis of this study, representing a response rate of $80.4 \%$. The respondents resided in various communities throughout the 14 parishes of the island, and represented a wide cross-section of occupational and educational status. The authors were therefore able to capture a wider range of responses than if any one community was targeted. Adult males and females aged 20-35 were targeted. Pregnant women and persons of unsound mind were excluded from the study.

All questions were contained in the 4-page (56 questions) self-administered questionnaire. Respondents filled out the questionnaires themselves and placed it in a sealed envelope that was collected by the medical professionals. The first part of the questionnaire contained questions on the socio-demographic data of the respondents, while the second section contained questions related to their
Table 1: Socio-demographic characteristics of respondents

\begin{tabular}{|c|c|c|c|c|}
\hline \multirow[b]{2}{*}{ Variables } & \multicolumn{2}{|c|}{$\operatorname{Men}(\mathrm{n}=125)$} & \multicolumn{2}{|c|}{ Women $(\mathrm{n}=88)$} \\
\hline & No. & $\%$ & No. & $\%$ \\
\hline \multicolumn{5}{|l|}{ Age (years) } \\
\hline $20-24$ & 2 & 1.6 & 4 & 4.5 \\
\hline $25-29$ & 22 & 17.6 & 24 & 27.3 \\
\hline $30-35$ & 103 & 82.4 & 60 & 68.2 \\
\hline \multicolumn{5}{|l|}{ Marital Status } \\
\hline Legally Married & 96 & 76.8 & 66 & 75.0 \\
\hline Unmarried & 29 & 23.2 & 22 & 25.0 \\
\hline \multicolumn{5}{|l|}{ Educational attainment } \\
\hline Elementary & 24 & 19.2 & 0 & 0.0 \\
\hline Primary & 7 & 5.6 & 1 & 1.1 \\
\hline Secondary & 83 & 66.4 & 66 & 75.0 \\
\hline Tertiary & 11 & 8.8 & 21 & 23.9 \\
\hline \multicolumn{5}{|l|}{ Occupation } \\
\hline Unemployed & 8 & 6.4 & 7 & 8.0 \\
\hline Self employed & 7 & 5.6 & 8 & 9.1 \\
\hline Seasonally employed & 20 & 16.0 & 12 & 13.6 \\
\hline Temporary employed & 58 & 46.4 & 26 & 29.5 \\
\hline Permanently employed & 32 & 25.6 & 35 & 39.8 \\
\hline \multicolumn{5}{|l|}{$\begin{array}{l}\text { Number of members } \\
\text { in household }\end{array}$} \\
\hline$<5$ & 15 & 12.0 & 4 & 4.5 \\
\hline $5-9$ & 110 & 88.0 & 24 & 27.3 \\
\hline $10-14$ & 0 & 0.0 & 60 & 68.2 \\
\hline
\end{tabular}

sexual activities and behavior. Standard demographic measures included sex, age, marital status, and educational level. In terms of sexual experience, respondents were asked whether they were sexually experienced, and whether they had sexual intercourse in the last 12 months prior to the administration of the questionnaire. Other questionnaire items asked respondents to indicate the number of lifetime sexual partners, as well as their sexual orientation. One questionnaire item asked respondents to indicate how often they had sexual intercourse in the last 12 months with primary and non-primary partners. For this item, three response categories were given-daily, more than once per week or once per month. In terms of multiple sex partners, respondents were asked if they had 1, 2-3 or more than 4 lifetime sexual partners. Respondents who reported using condoms every time during sexual intercourse with primary (defined as "a person to whom you are married or someone to whom you feel committed above anyone else") and non-primary partners were deemed as consistent condom users. In examining the variable STIs, the respondents reported symptoms of foul or unusual discharge from the sex organ, ulcer in or on the outside of the genitals and HIV.

The research also examines the relationship between frequency of sexual activities and variables such as marijuana smoking, use of other contraceptives, age at first sexual intercourse, number of children, and occupational status. The Statistical Package for Social 
Am. J. Infect. Dis., 4 (2): 109-116, 2008

Table 2: Sexual activity and behavioural patterns of respondents

\begin{tabular}{|c|c|c|c|c|}
\hline \multirow[b]{2}{*}{ Variables } & \multicolumn{2}{|c|}{$\begin{array}{l}\text { Men } \\
(\mathrm{n}=125)\end{array}$} & \multicolumn{2}{|c|}{$\begin{array}{l}\text { Women } \\
(\mathrm{n}=88)\end{array}$} \\
\hline & No. & $\%$ & No. & $\%$ \\
\hline \multicolumn{5}{|l|}{$\begin{array}{l}\text { Age at first sexual } \\
\text { experience (years) }\end{array}$} \\
\hline$<15$ & 14 & 11.2 & 16 & 18.2 \\
\hline $15-18$ & 93 & 74.4 & 70 & 79.5 \\
\hline $19-22$ & 18 & 14.4 & 0 & 0.0 \\
\hline$>22$ & 0 & 0.0 & 2 & 2.3 \\
\hline \multicolumn{5}{|l|}{ Sexual views } \\
\hline Positive & 121 & 96.8 & 57 & 64.8 \\
\hline Uncertain & 4 & 3.2 & 18 & 20.5 \\
\hline Negative & 0 & 0.0 & 17 & 14.8 \\
\hline \multicolumn{5}{|l|}{ Feel for sex } \\
\hline Frequently & 112 & 89.6 & 27 & 30.7 \\
\hline Occasionally & 13 & 10.4 & 57 & 64.8 \\
\hline Rarely & 0 & 0.0 & 4 & 4.5 \\
\hline \multicolumn{5}{|l|}{$\begin{array}{l}\text { Frequency of sexual } \\
\text { intercourse }\end{array}$} \\
\hline Daily & 62 & 49.6 & 2 & 2.3 \\
\hline More than once per week & 41 & 32.8 & 67 & 76.1 \\
\hline Once per month & 22 & 17.6 & 19 & 21.6 \\
\hline \multicolumn{5}{|l|}{ Sexual satisfaction } \\
\hline Yes & 100 & 100 & 21 & 23.9 \\
\hline No & 0 & 0.0 & 61 & 69.3 \\
\hline Not certain & 0 & 0.0 & 6 & 6.8 \\
\hline \multicolumn{5}{|l|}{ Number of Children } \\
\hline None & 0 & 0.0 & 25 & 29.8 \\
\hline $1-3$ & 12 & 9.6 & 39 & 46.4 \\
\hline $4-6$ & 64 & 51.2 & 6 & 7.1 \\
\hline $7-9$ & 24 & 19.2 & 14 & 16.7 \\
\hline$>10$ & 25 & 20.0 & 0 & 0.0 \\
\hline \multicolumn{5}{|l|}{$\begin{array}{l}\text { Number of sexual } \\
\text { partners }\end{array}$} \\
\hline 1 & 15 & 12.0 & 80 & 90.0 \\
\hline $2-3$ & 101 & 80.8 & 8 & 9.1 \\
\hline $4+$ & 9 & 7.2 & 0 & 0.0 \\
\hline
\end{tabular}

Scientists (SPSS, Chicago, IL) was used to analyze the data. Both bivarate (chi square) and multivariate (logistic regression) analyses were used to examine the data.

\section{RESULTS AND DISCUSSION}

A total of 213 ( 88 women and 125 men) out of the 265 questionnaires distributed to the adults were satisfactory completed thus met the criteria for the study. Table 1 shows the socio-demographic characteristics of the respondents. Of the women in the sample, $4.5 \%$ was in age group $20-24 ; 27.3 \%$ in age group $25-29$ and $68.2 \%$ in age group $30-35$. Of the men in the sample, $1.6 \%$ was in age group aged 20-24; $17.6 \%$ in age group $25-29$ and $82.4 \%$ in age group 30-35. Data on educational attainment indicate that the majority of the respondents $(75.0 \%$ women and $66.4 \%$ men) had achieved secondary education; followed by tertiary education $(23.9 \%$ women and $8.8 \%$ men), elementary education ( $0 \%$ of women and $19.2 \%$ men) and primary education (1.1\% women and $5.6 \%$ men). The difference in educational attainment between women and men was statistically significant $\left(\chi^{2}=27.89, \mathrm{p}<0.05\right)$.

All the respondents in the sample reported that they were heterosexuals, sexually active and experienced. The majority of the respondents had their first sexual experience when they were 15-18 years old, with $79.5 \%$ of men and $74.4 \%$ of women (Table 2). Among the men, the majority frequently had the need for sex (89.6\%); had a positive view of sex (96.8\%); achieved sexual satisfaction $(100.0 \%)$ and had sexual intercourse daily $(49.6 \%)$, and had $4-6$ children $(51.2 \%)$. On the other hand, the majority of women had positive view of sex (64.8\%); did not achieve full sexual satisfaction (69.3\%); had sexual intercourse more than once per week (76.1\%) and had 1-3 children (46.4\%). The differences between men and women were statistically significant for the variables: sexual views $\left(\chi^{2}=40.57\right.$, $\mathrm{p}<0.05)$, feels for $\operatorname{sex}\left(\chi^{2}=79.61, \mathrm{p}<0.05\right)$, enjoy sex $\left(\chi^{2}=138.85, \mathrm{p}<0.05\right)$ and frequency of sexual intercourse $\left(\chi^{2}=58.05, p<0.05\right)$. Men reported a higher number of sexual partners than women. According to the data, $12.0 \%$ and $80.6 \%$ of sexually active men reported having 1 and 2-3 sexual partners respectively. This compared with $90.9 \%$ and $9.1 \%$ of women having 1 and 2-3 sexual partners respectively $\left(\chi^{2}=130.33\right.$, $\mathrm{p}<0.05)$.

Among the respondents who had sex daily, $79.7 \%$ was in the age group 30-35 whilst of those who had sex more than once per week, $74.1 \%$ was also in the age group 30-35 (Table 3). Among those who had sexual intercourse once per month, $68.3 \%$ was in the $20-24$ age group. The majority of those who had sexual intercourse daily were married $(82.8 \%)$; attained secondary school education (59.4\%) and temporarily employed (45.3\%); had 5-9 persons in their households (92.2\%) and 4-6 children (50.0\%); had first sexual experience when aged 15-18 (59.4\%); frequently had the need for sex $(96.9 \%)$ and achieved full sexual satisfaction (100.0\%); had positive view of sex $(98.4 \%)$ and did not smoke marijuana (87.5\%). Those who had sex more than once per week were mostly married (67.6\%); attained secondary school education (66.7\%) and were permanently employed (44.4\%). They also had 5-9 persons in their households $(64.8 \%)$ with 1-3 children (34.3\%); had their first sexual experience when aged 15-18 (78.7\%); frequently had the need for sex $(55.6 \%)$ and enjoyed having sex (55.6\%); had positive views of sex $(80.6 \%)$ and did not smoke marijuana (94.4\%). Likewise, the majority of those who had sexual intercourse once per month were married 
Am. J. Infect. Dis., 4 (2): 109-116, 2008

Table 3: Comparison of sexual activity with socio-demographic and behavioural factors

\begin{tabular}{|c|c|c|c|c|c|c|}
\hline \multirow[b]{3}{*}{ Variables } & \multicolumn{6}{|c|}{ Frequency of sexual activity } \\
\hline & \multicolumn{2}{|c|}{ Daily } & \multicolumn{2}{|c|}{$\begin{array}{l}\text { More than once } \\
\text { per week }\end{array}$} & \multicolumn{2}{|c|}{ Once per month } \\
\hline & No. & $\%$ & No. & $\%$ & No. & $\%$ \\
\hline \multicolumn{7}{|l|}{ Age } \\
\hline $20-24$ & 1 & 1.6 & 0 & 0.0 & 28 & 68.3 \\
\hline $25-29$ & 12 & 18.8 & 28 & 25.9 & 5 & 12.2 \\
\hline $30-35$ & 51 & 79.7 & 80 & 74.1 & 8 & 19.5 \\
\hline \multicolumn{7}{|l|}{ Marital status } \\
\hline Married & 53 & 82.8 & 73 & 67.6 & 36 & 87.8 \\
\hline Unmarried & 11 & 17.2 & 35 & 32.4 & 5 & 12.2 \\
\hline \multicolumn{7}{|l|}{ Occupation } \\
\hline Unemployed & 2 & 4.9 & 11 & 10.2 & 2 & 4.9 \\
\hline Self employed & 7 & 10.9 & 2 & 1.9 & 6 & 14.6 \\
\hline Seasonally employed & 13 & 20.3 & 5 & 4.6 & 14 & 34.1 \\
\hline Temporary employed & 29 & 45.3 & 42 & 38.9 & 13 & 31.7 \\
\hline Permanently employed & 13 & 20.3 & 48 & 44.4 & 6 & 14.6 \\
\hline \multicolumn{7}{|l|}{ Educational attainment } \\
\hline Elementary & 15 & 23.4 & 9 & 8.4 & 0 & 0.0 \\
\hline Primary & 0 & 0.0 & 7 & 6.5 & 1 & 2.4 \\
\hline Secondary & 38 & 59.4 & 72 & 66.7 & 39 & 95.1 \\
\hline Tertiary & 11 & 17.2 & 20 & 18.5 & 1 & 2.4 \\
\hline \multicolumn{7}{|l|}{$\begin{array}{l}\text { Number of members } \\
\text { in household }\end{array}$} \\
\hline$<5$ & 5 & 7.8 & 24 & 22.2 & 2 & 4.9 \\
\hline $5-9$ & 59 & 92.2 & 70 & 64.8 & 39 & 95.1 \\
\hline $10-14$ & 0 & 0.0 & 14 & 13.0 & 0 & 0.0 \\
\hline \multicolumn{7}{|l|}{ Number of Children } \\
\hline None & 1 & 1.6 & 22 & 21.0 & 2 & 5.0 \\
\hline $1-3$ & 4 & 6.3 & 36 & 34.3 & 11 & 27.5 \\
\hline $4-6$ & 32 & 50.0 & 33 & 31.4 & 5 & 12.5 \\
\hline $7-9$ & 15 & 23.4 & 14 & 13.3 & 9 & 22.5 \\
\hline$>10$ & 12 & 18.8 & 0 & 0.0 & 13 & 32.5 \\
\hline \multicolumn{7}{|l|}{$\begin{array}{l}\text { Age at first sexual } \\
\text { experience (years) }\end{array}$} \\
\hline$<15$ & 13 & 20.3 & 17 & 15.7 & 0 & 0.0 \\
\hline $15-18$ & 38 & 59.4 & 85 & 78.7 & 40 & 97.6 \\
\hline $19-21$ & 13 & 20.3 & 5 & 4.6 & 0 & 0.0 \\
\hline$>21$ & 0 & 0.0 & 1 & 0.9 & 1 & 2.4 \\
\hline \multicolumn{7}{|l|}{ Feel for sex } \\
\hline Frequently & 62 & 96.9 & 60 & 55.6 & 17 & 41.5 \\
\hline Occasionally & 0 & 0.0 & 1 & 0.9 & 3 & 7.3 \\
\hline Rarely & 2 & 3.1 & 47 & 43.5 & 21 & 51.2 \\
\hline \multicolumn{7}{|l|}{ Enjoy sex } \\
\hline Yes & 64 & 100.0 & 60 & 55.6 & 22 & 53.7 \\
\hline No & 0 & 0.0 & 43 & 39.8 & 18 & 43.9 \\
\hline Not certain & 0 & 0.0 & 5 & 4.6 & 1 & 2.4 \\
\hline \multicolumn{7}{|l|}{ Sexual views } \\
\hline Positive & 63 & 98.4 & 87 & 80.6 & 28 & 68.3 \\
\hline No & 0 & 0.0 & 13 & 12.0 & 5 & 12.2 \\
\hline Not certain & 0 & 0.0 & 8 & 7.4 & 8 & 19.5 \\
\hline \multicolumn{7}{|l|}{ Marijuana smoking } \\
\hline None & 56 & 87.5 & 102 & 94.4 & 23 & 73.2 \\
\hline Once per month & 0 & 0.0 & 1 & 0.9 & 10 & 24.4 \\
\hline Once weekly & 1 & 1.6 & 2 & 1.9 & 1 & 2.4 \\
\hline Daily & 7 & 10.9 & 3 & 2.8 & 0 & 0.0 \\
\hline
\end{tabular}

(87.8\%); attained secondary school education (95.1\%) and seasonally employed (34.1\%); had 5-9 persons in their households $(95.1 \%)$ and greater than 10 children (32.5\%); had first sexual experience when aged 15-18
(97.6\%); did not always had the need for sex (51.2\%) and enjoyed having sex (53.7\%); had positive view of sex $(68.3 \%)$ and did not smoke marijuana $(73.2 \%)$. The majority of the respondents had 2-3 sexual partners 
Am. J. Infect. Dis., 4 (2): 109-116, 2008

Table 4: Number of sexual partners of respondents who use contraceptives and have been infected with sexually transmitted infections

\begin{tabular}{|c|c|c|c|c|c|c|c|c|}
\hline $\begin{array}{l}\text { Number of sexual } \\
\text { Partners }\end{array}$ & $\begin{array}{l}\text { Number of persons } \\
\text { with sexual } \\
\text { partners }\end{array}$ & No contraceptive & Condoms & Pills & Coil & Injection & Others & STIs \\
\hline \multirow[t]{2}{*}{1} & 95 & 71 & 43 & 40 & 5 & 13 & 9 & 8 \\
\hline & $44.6 \%$ & $53.4 \%$ & $41.3 \%$ & $95.2 \%$ & $100 \%$ & $100 \%$ & $45.0 \%$ & $12.5 \%$ \\
\hline \multirow[t]{2}{*}{$2-3$} & 109 & 60 & 59 & 2 & 0 & 0 & 10 & 55 \\
\hline & $51.2 \%$ & $45.1 \%$ & $56.7 \%$ & $4.8 \%$ & $0.0 \%$ & $0.0 \%$ & $50.0 \%$ & $85.9 \%$ \\
\hline \multirow[t]{2}{*}{$4+$} & 9 & 2 & 2 & 0 & 0 & 0 & 1 & 1 \\
\hline & $4.2 \%$ & $1.5 \%$ & $1.9 \%$ & $0.0 \%$ & $0.0 \%$ & $0.0 \%$ & $5.0 \%$ & $1.6 \%$ \\
\hline Total & 213 & 113 & 104 & 42 & 5 & 13 & 20 & 64 \\
\hline
\end{tabular}

$(51.2 \%)$. Very few persons had 4 or more partners (4.2\%) and $44.6 \%$ had only one sex partner (Table 4 ). The use of condoms was highest among those with 2-3 partners $(56.7 \%)$ and least among those with 4 and more partners $(1.9 \%)$. Condom use was also highest in the 30-35 age group. The respondents with 2-3 sexual partners ranked highest among those with STIs $(85.9 \%)$ and least among those with 4 or more partners (1.6\%). The use of other contraceptive methods was prevalent among those who had 1 sexual partner, $12.5 \%$ of whom had contracted STIs. The non-use of contraceptive was highest among those with one sex partner (53.4\%), followed by those who had 2-3 partners (45.1\%) and least among those with 4 or more partners $(1.5 \%)$.

The findings of this study confirmed a high level of sexual activity among young adults in Jamaica. In examining the factors that predicted sexual outcomes, frequency of sexual activity was slightly greater in women while sexual satisfaction was greater in men. The results suggest that a large proportion of adults are engaged in risky sexual behaviors. Risk factors observed were multiple sexual partners, early sexual initiation and inconsistent condom use. This suggests therefore that young adults are not protecting themselves against STIs and unplanned pregnancies. Our analyses yield findings that will be of use to health care practitioners, health educators and policy makers seeking to reduce young adult's risk of infection with HIV and other STIs.

Men and women have sex for different reasons in different ways and in different settings. Advances in contraception, and the availability of contraceptives and increased access to family planning services in Jamaica have increasingly freed sexual expression from its reproductive consequences. Most of the respondents in the study were married. Men had a more positive view of sex, felt frequently for sex, and had greater sexual satisfaction than women. Couples appreciation for their relationship is positively associated with higher sexual satisfaction. Psychological factors such as stress, anxiety and depression have impact on couples sexual functioning. For example, marital difficulties and sexual problems are interrelated ${ }^{[7]}$. Negative thoughts about self, the partner and the relationship, which characterize psychological stress are strongly associated with the quality of both the general and sexual aspect of the relationship ${ }^{[8]}$. Some of the male patients who were diabetics expressed that they were experiencing some degree of erectile dysfunction. This is usually as a result of reduced blood flow and damage to the peripheral nerves. In the case of the diabetic female, however, sex becomes uncomfortable because of apparent decreased lubrication, frequent yeast infection and vaginitis.

Drug abuse is a major concern among adults in Jamaica and many adults are involved in the smoking of marijuana. In our study only $15.5 \%$ of the respondents smoked marijuana and most of them had sex once monthly. A study conducted by Zharkov addressing sexual activities among marijuana and heroin abusers (males and females) noted that there is a significant reduction in sexual intercourse in males ${ }^{[9]}$. Libido had been decreased and platonic affection is absent. Reduced libido in the female may occur as a result of anaemia, post-child birth, diabetes mellitus, drug abuse, and hyperprolactinaemia. On the other hand, reduced libido in men is possibly because of alcoholism, drug abuse (heroine/cocaine), depression/stress, low testosterone, obesity, problems with a sexual partner or wife, and hyperprolactinaemia. There were more women in the study with secondary and tertiary education than men. With the exception of tertiary, increased educational attainment is associated with increased number of children. Respondents with secondary education had the most children with majority of these having between 4-6 children. The reasons for the number of children produced among the various literacy groups were expansion of generation; the fear that oral contraceptives could damage their health; security of relationship; the out-side male partners ('baby-fathers') the more money for child support; ignorance; a show of manhood; not wanting to be referred to as being 'barren' and for specific religious reasons. In Caribbean countries such as Jamaica, there have been increasing proportions of women with 
secondary and tertiary education resulting in a greater likelihood that they will delay entry into first unions and the onset of pregnancy. The attainment of higher levels of education in conjunction with increased labour force participation may also reduce the desired number of births and ideal family size, as women are increasingly exposed to lifestyles that render children more costly. Thus, it is expected that there will be a greater thrust in the direction of spacing and limiting births to attain desired fertility levels.

Having multiple sex partners is common among adults in Jamaica as confirmed by this study where 55.4 $\%$ of the respondents had more than one sexual partner. In Caribbean countries like Jamaica, there have been numerous instances in which single mothers have been known to sustain relationships with multiple partners primarily for economic reasons. This predisposes such women to risky sexual practices that expose them to STIs including HIV/AIDS. In such situations the men are known to wield considerable power over decisions concerning contraceptive use and sexual activities, hence they coerce women into having unprotected sex. This is further compounded by the "machismo" image of male dominance in sexual relationships in Jamaica. Women might be disadvantaged in protecting their sexual health if their partner is older than they, of higher social status ${ }^{[10]}$ or if they are beholden to a man for favours, goods or money in return for $\operatorname{sex}^{[11]}$. In addition, economic adversity restricts the power of men and women to take control of their health. Deprivation and unemployment might drive men and women to sell sex ${ }^{[12]}$ or travel greater distances to work. Being away from home is associated with concurrency of partnership and an increased in risk behavior ${ }^{[13]}$. Henry ${ }^{[14]}$ reported that Jamaican men have five or more sexual partners per year, and there is widespread acceptance of sex outside of marriage or other stable relationships. However, in recent years Jamaican men who once readily have five or more sex partners per year are choosing their partners more carefully and staying in relationships longer. Women also report having fewer sex partners and young male adolescents are waiting until they are older to begin having sex.

Sexually transmitted infections are a personal, public health and economic issues of serious concern throughout the world, and have health consequences for men, women, children and the society as a whole. There is a common acceptance of STIs as a natural and easily curable outcome of sexual activity ${ }^{[14]}$. In this study a number of respondents had a history of more than one STIs. Approximately $86 \%$ of respondents with 2-3 partners had STIs. Among women attending family planning clinics, $27 \%$ of them had at least one
STI. There is a strong association between STIs and HIV infection in Jamaica, with 39\% of persons living with HIV/AIDS having a previous history of sexually transmitted infection ${ }^{[15]}$. There is substantial evidence that STIs may increase the susceptibility of uninfected individuals to HIV and also increase the infectiousness of HIV-positive individuals. There is a report of almost $50 \%$ of the syphilis and gonorrhoea cases in Jamaica among adolescent ${ }^{[16]}$ and $33 \%$ of them studied by Smikle and colleagues had repeated episodes of STIs and $1.2 \%$ reported HIV coinfection with other STIs ${ }^{[17]}$. In $1999,20 \%$ of all cases of genital discharge syndrome were among persons aged 10-24 years. In addition, in the age group 15-19 years, rates of infectious syphilis were 10.8 cases per 100,000 males and 14.4 cases per 100,000 females during the same period ${ }^{[18]}$.

The condom was the main form of contraceptive used by respondents in the study and its use was highest among those with 2-3 partners. In our study, condom use was highest in the 30-35 age group and a large proportion of the respondents are married. Married women find negotiation of safer sex and use of condoms for family planning more difficult than do single women. Data from national Knowledge Attitudes Behaviours and Practices (KABP) surveys in Jamaica shows that approximately $25 \%$ of men and $34 \%$ of women did not use a condom at last sexual encounter with a non-regular sexual partner ${ }^{[19]}$. Three national surveys conducted in Jamaica among persons aged 15-49 years showed increases in condom use. From 1989 to 1993, the proportion of those reporting ever using condoms increased from $53 \%$ to $79 \%$. Consistent condom use (defined as use every time) with one's partner increased from $27 \%$ to $41 \%{ }^{[20]}$. These changes are likely to be due to widespread awareness of HIV/AIDS and the programmes to promote safe sexual behavior. As a result of extensive behavior change and communication interventions, knowledge of HIV/AIDS is high (97\%) and condom use with non-regular adult partners has increased from $37 \%$ in 1992 to $67 \%$ in 2000. Condoms are also available in traditional and non-traditional outlets and a 24-hour AIDS/STI Helpline caters to those requiring private and confidential counseling and information ${ }^{[21]}$.

The youth age group 10 to 24 comprises nearly one-thirds of Jamaica's total population of over 2.6 million $^{[22]}$. Age of sexual initiation is of public interest, since early initiation is more likely to be nonconsensual and to be subsequently regretted, less likely to be protected against unplanned pregnancy and infection, and associated with a larger lifetime numbers of sexual partners ${ }^{[23]}$. Most of the respondents in this study had their first sexual experience in the later 
teenage years (15-18 year old). According to the Jamaica Reproductive Health Survey of 2002-2003, among youths aged 15-24, the mean age of first sexual intercourse was 13.5 years among males and 15.8 among females ${ }^{[23]}$. In a 2001 survey of more than 1,000 adolescents, $73.7 \%$ of $15-19$ year olds and $9.5 \%$ of $10-14$ year olds reported to be sexually active $e^{[23]}$. This level of sexual activity among such children adolescents can therefore be seen in the context of an opulent and permissive environment that favours the attraction and interaction of the opposite sex and which, therefore, inevitably predisposes them to express themselves sexually. Adolescents and young adults in Jamaica are also socialized by a culture that is conducive to increased levels of early and frequent sexual activity. The Jamaican culture promotes early sexual activity and multiple partnerships for males, especially among adolescents and young adults. The adoption of multiple partnerships increases the likelihood of both primary and secondary exposure to STI, including HIV infection ${ }^{[24]}$.

There are some limitations that may have impacted on the findings. The questionnaire had a number of sex-related sensitive items. Data of this of this nature are likely to contain some bias. Intentional misreporting, incomplete recall and misunderstanding of survey questions could reduce both the reliability and the internal validity of the data. Despite education and awareness programmes that have been in place for years, a substantial number of adults especially young men in Jamaica continue to practice high-risk sexual behaviours. The probability of the transmission of HIV/AIDS and other STIs with high-risk behaviors remains significant. In addition, comprehensive behavioral interventions are needed that take into account the social context, attempt to modify social norms to support uptake and maintenance of behavioral change, and tackle the structural factors that contribute to risky sexual behavior. There needs to be genderspecific information and services that address young women's needs and pay attention to their less than equal power status in many relationships. Efforts should also focus on such priority areas as behavior change and improve communication to encourage safe sex practices and a delay in the initiation of sexual activity. There is a critical need for innovative programs that address the cultural aspects of sexually in Jamaica and promote consistent condom use with all partners during every episode of sexual intercourse. Strengthening the diagnosis and management of STIs among those who are sexually active and expanding and improving the quality of these preventative programmes could have a positive impact on decreasing the transmission of STIs including HIV/AIDS infection. In addition, a preventative programme for STIs including HIV/AIDS should tackle social, cultural and economic factors that may fuel the transmission of such disease(s).

\section{REFERENCES}

1. Edwards, J., A. Booth, 1994. A. Sexuality, marriage, and well-being: The middle years. In A. S. Rossi (Ed.), Sexuality across the life course. Chicago: The University of Chicago Press, pp: 233-259.

2. Warner, P., J. Bancroft, 1988. Mood, sexuality, oral contraceptives and the menstrual cycle. Journal of Psychosomatic Research, 32: 417-427.

3. Ebrahim, S., M. May, Y. Ben Shlomo, P. McCarron, S. Frankel, J. Yarnell and G. Davey Smith, 2002. Sexual intercourse and risk of ischaemic stroke and coronary heart disease: The Caerphilly Study. Journal of Epidemiology Community Health, 56: 99-102.

4. Petridou E., G. Giokas, H. Kuper, L. Mucci and D. Trichopouloset, 2000. Endocrine correlates of male breast cancer risk: A Case-Control Study in Athens, Greece. British J. Cancer, 83: 1234-1237.

5. Figueroa, J.P., K. Fox and K. Minor, 1999. A behaviour risk factor survey in Jamaica. West Indian Medical Journal, 28: 9-15.

6. Ministry of Health-National HIV/STD Prevention and Control Program Jamaica, 1993-2000.

7. Zimmer, D., 1987. Does marital therapy enhances the effectiveness of treatment for sexual dysfunction? J. Sex and Marital Therapy, 13: 193-209.

8. Gottman, J., N. Silver, 1999. Principle 2: Nurture your fondness and admiration in The Seven Principles for Making Marriage Work (Chapter 4). New York: Three Rivers Press (Random House, Inc), 61-77.

9. Zharkov, Y., 2002. Sexuality of heroin addicts: Applied aspects of studies. National Research Centre on addictions, rehabilitation Department, Muscow, Russia. European Journal of Medical Sexology, XI-N39: 44.

10. Bajos, N., J. Marquet, 2000. Research on HIV sexual risk: social relations-based approach in a cross-cultural perspective. Soc. Sci. Med., 50: $1533-1546$.

11. Amaro, H., W. De Jong, S. Gortmaker and R. Rudd, 2000. Relationship power, condom use and HIV risk among women in the USA. AIDS Care, 44: 789-800. 
12. Simon, S. and S.J. Paxton, 2004. Sexual risk attitudes and behaviours among young adult Indonesians. Cultr. Health Sex, 6: 393-409.

13. Fuber, A.S., J.N., Newell and M.M. Lubben, 2002. A systematic review of current knowledge of HIV epidemiology and sexual behaviour in Nepal. Trop. Med. Int. Health, 7: 140-148.

14. Henry, K., 1997. Jamaicans begin to embrace safer sex. Aidscaptions, 4: 18-22.

15. World Bank, 2002. Jamaica-HIV/AIDS Prevention and Control Project (second phase of the multi-country HIV/AIDS prevention \& control APL for the Caribbean), Washington DC: World Bank.

16. Kauffman, C. and L. Hue, 1997. Sustaining youth peer HIV/STD prevention education. AIDSSTD Health Promotion Exch., 3: 3-7.

17. Smikle, M.F., G. Dowe, T. Hylton-Kong, E. Williams and M. Baun, 2000. Risky behaviour in Jamaican adolescent patients attending a sexually transmitted disease clinic. West Indian Medical Journal, 49: 327-330.
18. Ministry of Health, 2000. Summary of STD cases in Jamaica, 1999. Kingston, Jamaica: Ministry of Health.

19. Hope Enterprises. National KABP Surveys 1992, 1994, 1996, 2000, Kingston.

20. Figueroa, J., A. Braithwaite, S. Samile, P. Weller, L. Byfield and M. Wedderburn, 1994. Increased condom use in Jamaica. Int. Conf. AIDS, PC0495.

21. Ministry of Health, 2005. Draft National HIV/AIDS Policy Jamaica, April 2005.

22. Population Reference Bureau, 2006. The World's Youth 2006 Data Sheet. Washington, DC: PRB.

23. Dickson, N., C. Paul, P. Herbison and P. Silva, 1998. First intercourse: age, coercion, later regrets reported by a birth cohort. B.M.J., 361: 29-33.

24. Norman, L., C. Uche, 2002. Prevalence and determinants of sexually transmitted diseases. Sexually Transmitted Diseases, 29: 126-132. 